\title{
PERANAN BLENDED LEARNING TERHADAP EVALUASI PEMBELAJARAAN TEMATIK DI SEKOLAH DASAR
}

\author{
Reza Maulana ${ }^{1}$, Wahyu Lestari ${ }^{2}$ \\ ${ }^{1}$ PGSD Universitas Negeri Semarang \\ 2Universitas Negeri Semarang \\ ${ }^{1}$ Rezamaulana97@students.unnes.ac.id \\ $\underline{2}$ wahyupyarlestari@mail.unnes.ac.id \\ No. hp085719537003
}

\begin{abstract}
The purpose of this study is to analyze the role of Blended Learning learning program to evaluate thematic learning in thematic elementary school in terms of context, input, process, SD Insan Kamil Bogor. This type of research is descriptive with a qualitative approach. The subjects of this study were principals, grade IV teachers, and grade IV students. Data collection techniques using interviews, observations, questionnaires, and documentation. The assessment criteria as the evaluation benchmark in this study refers to the reference that has been made. The results showed that (1) the thematic learning context component in Insan Kamil Bogor based on the results of interviews with principals and teachers fall into the good category. Learning objectives that are in accordance with the analysis of needs but tend not to be implemented consequently in the thematic learning process because the teacher does not understand the background and the importance of the implementation of thematic learning programs for students in the early grades; (2) the input components of syllabus and RPP aspects, learning facilities, and learning motivation in general are in the excellent category; (3) the process component of the teacher performance aspect in the classroom in general falls into the category of less because so far the teacher has not been maximal in teaching thematic and is more likely to teach the subjects only. It is recommended to teachers and policy makers to be able to conduct innovative evaluations and activities so that thematic learning programs can run as much as possible.
\end{abstract}

Keywords: Blended Learning, Teachers, Students, Thematic Learning Evaluation, Innovative.

\section{ABSTRAK}

Tujuan penelitian ini untuk menganalisis program pembelajaraan peranan Blended Learning terhadap evaluasi pembelajaraan tematik di sekolah dasar tematik dari segi konteks, input, proses, SD Insan Kamil Bogor. Jenis penelitian ini adalah deskriptif dengan pendekatan kualitatif. Subjek penelitian ini adalah kepala sekolah, 
guru kelas IV, dan siswa kelas IV. Teknik pengumpulan data menggunakan wawancara, observasi, angket, dan dokumentasi. Kriteria penilaian sebagai tolok ukur evaluasi dalam penelitian ini merujuk pada acuan yang telah dibuat. Hasil penelitian menunjukkan bahwa (1) komponen konteks pembelajaraan tematik di Sekolah Insan Kamil Bogor berdasarkan hasil wawancara dengan kepala sekolah dan guru masuk dalam kategori baik. Tujuan pembelajaraan yang sesuai dengan analisis kebutuhan namun cenderung tidak dilaksanakan dengan konsekuen di dalam proses pembelajaraan tematik karena guru belum memahami betul latarbelakang dan arti penting dilaksanakannya program pembelajaraan tematik bagi siswa di kelas awal; (2) komponen input aspek silabus dan RPP (Rencana Pelaksanaan Pembelajaraan), fasilitas belajar, dan motivasi belajar secara umum berada pada kategori sangat baik; (3) komponen proses dari aspek kinerja guru dalam kelas secara umum masuk dalam kategori kurang karena selama ini guru belum maksimal dalam mengajarkan tematik dan lebih cenderung mengajarkan mata pelajaran saja. Disarankan kepada para guru dan penentu kebijakan agar dapat melakukan evaluasi dan kegiatan-kegiatan yang inovatif agar program pembelajaraan tematik dapat berjalan semaksimal mungkin.

Kata kunci: Blended Learning, Guru, Siswa, Evaluasi Pembelajaraan Tematik, Inovatif

\section{A. Pendahuluan}

Model pembelajaraan merupakan krangka yang menggambarkan prosedur yang dirancang secara sistematis agar sistem belajar mengajar terorganisir dengan baik. Fungsi adanya model pembelajaraan dalam kegiatan KBM (Kegiatan Belajar Mengajar) membantu guru membuat pola yang berfungsi sebagai pedoman dalam kegiatan mengajar sehingga tumbuh kembang siswa dalam aspek-aspek yang diharapkan baik dalam moral dan pengetauan berkembang dengan baik.
Penerpan model pembelajaraan dalam proses KBM tidak dapat dipisahkan, terlebih pada masa pandemic ini guru masih kesulitan memilih model pembelajaraan dan media yang sesuai keadaan, oleh sebab itu penggunaan media berbasis teknologi adalah salah satu sistem yang paling efektif digunkan pada proses pembelajaraan.

Penggunan model Blended Learning dan penggunaan media berbasis teknologi mampu menjembatani siswa dengan guru dalam KBM pada masa pandemic ini. Menurut Thorne (2013), Blended 
Didaktik : Jurnal IImiah PGSD STKIP Subang, ISSN Cetak : 2477-5673 ISSN Online : 2614-722X Volume 07 Nomor 01, Juni 2021

Learning adalah campuran dari teknologi E-learning dan multimedia, seperti video streaming, virtual class, animasi teks online yang dikombinasikan dengan bentukbentuk tradisional pelatihan di kelas. Sementara Graham (2005) menyebutkan Blended Learning secara lebih sederhana sebagai pembelajaraan yang mengkombinasikan antara pembelajaraan online dengan face-toface (pembelajaraan tatap muka). Artinya, Blended Learning merupakan campuran dari strategi pembelajaraan dan metode penyampaian yang mampu mengoptimalkan pengalaman dan hasil belajar yang diharapkan.

Evaluasi merupakan unsur penting dalam proses KBM evaluasi meupakan proses penentuan tingat pencapaian hasil belajar melalui berbagai cara yang dilakukan guru baik dalam bentuk kongnitif, afektif dan psikomotor dan sebelumnya telah disusun secara sistematis. Menurut Wrightstone dkk, (Ngalimun Purwanto, 2011) evaluasi sebagai penaksiran terhadap pertumbuhan dan kemajuan siswa kearah tujuan atau nilai-nilai yang telah ditetapkan dalam kurikulum.
Berdasarkan

Permendikbud Nomor 20 Tahun 2016 mengenai Standar Kompetensi Lulusan Pendidikan Dasar dan Menengah yang digunakan sebagai acuan utama pengembangan standar isi, proses, penilaian pendidikan, pendidik, tenaga kependidikan, sarana, prasarana, pengelolaan, dan standar pembiayaan.

Berdasarkan Permendikbud Nomor 21 Tahun 2016 mengenai Standar Isi Pendidikan Dasar dan Menengah yang memuat tentang Tingkat Kompetensi dan Kompetensi Inti sesuai dengan jenjang dan jenis pendidikan tertentu. Kompetensi inti meliputi sikap spiritual, sikap sosial, pengetahuan dan keterampilan. Berdasarkan Permendikbud Nomor 22 Tahun 2016 tentang Standar Proses Pendidikan Dasar dan Menengah merupakan kriteria mengenai pelaksanaan pembelajaraan pada satuan jenjang pendidikan dasar menengah untuk mencapai kompetensi lulusan.

Menurut Sunarti dan Rahmawati (2014), penilaian pendidikan adalah proses pengumpulan dan pengolahan informasi yang mencakup penilaian murni yang digunakan dalam berbagai teknik penilaian, penilaian yang 
Didaktik : Jurnal IImiah PGSD STKIP Subang, ISSN Cetak : 2477-5673 ISSN Online : 2614-722X Volume 07 Nomor 01, Juni 2021

digunaan oleh guru bisa mencakup ulangan harian, tengah semester, akhir semester, ujian tingkat kompetensi, ujian mutu tingkat kompetensi, ujian nasional, sampai ujian sekolah yang bertujuan untuk mengetahui perkembangan siswa dari hasil belajarnya. Selain itu, penilaian dilakukan untuk mengetahui proses dan hasil belajar siswa untuk memperbaiki dan meningkatkan kualitas pembelajaraan. Melalui evaluasi guru dapat megetahui dan mengukur kemampuan siswa yang sebelumya telah ditetapkan oleh pemerintah melalui kurikulum dalam pembelajaraan tematik.

Pembelajaraan tematik merupakan suatu usaha memadukan pengetahuan secara menyeluruh dan terintegrasi. Pembelajaraan tematik merupakan salah satu pendekatan integrasi secara alami menghubungkan fakta-fakta dan ideide dalam upaya untuk memahami dunia. Siswa dapat menghubungkan ide-ide dan pengalaman dengan lingkungan tempat tinggalnya melalui teknologi. Pembelajaraan tematik adalah suatu model terapan pembelajaraan terpadu yang mengintegrasikan beberapa mata pelajaran dalam satu kesatuan yang terikat oleh tema (Fogarty, 1991, hlm. 54). Tema sebagai pengait antara sub tema dari satu mata pelajaran dengan mata pelajaran lainnya

\section{B. Metode Penelitian}

Penelitian ini menggunakan metode penelitian kualitatif deskriftf karena hasil dari penelitian ini disajikan peneliti metlalui observasi partisipan dan wawancara mendalam terhadap guru dan siswa SD Insan Kamil Bogor. Menurut Sugiyono (2017) data yang disajikan peliti dalam penelitian dapat diukur dengan statistic. Penelitian ini juga dipaparkan oleh peneliti melalui deskriftif.

Teknik pengumpulan data pada penelitian ini adalah dengan mengumpulkan data melalui hasil observasi partisipan, wawancara mendalam, dan menggunakan angket untuk mengetahui informasi dari responden mengenai peranan Blended Learning terhadap evaluasi pembelajaraan tematik di sekolah dasar, serta dokumentasi. Pada proses wawancara dengan merekam dan mencatat data yang telah ditemukan serta dikumpulkan lalu akan dianalisis oleh peneliti. Hasil dari 
analisis data pada penelitian ini, peneliti mencoba untuk memperinci agar memudahkan peneliti dalam menganalisis data tersebut yaitu dengan beberapa tahap; (1)mengumpulkan data, hasil wawancara observasi dan angket akan dikumpulkan, dan disajikan oleh peneliti dalam bentuk data. (2)mengidentifikasi data. (3)mengklasifikasikan data, hasil dari penelitian ini akan dikelompokan berdasarkan jenis kriteria instrumen yang sudah dibuat peneliti. (4)mendeskrifsikan data, secara jelas dan terperinci mengenai hasil data yang diperoleh. (5)menyimpulkan data, kesimpulan dari data keseluruhan yang berbentuk hasil dan dari analisis data yang telah dilakukan oleh peneliti.

Fokus evaluasi program pembelajaraan tematik meliputi: (1)Aspek konteks adalah tujuan pembelajaraan tematik, lingkungan sekolah, dan kebutuhan pada pembelajaraan tematik,(2) Aspek input adalah silabus dan RPP ( Rencana Pelaksanaan Pembelajaraan), fasilitas belajar, dan motivasi belajar siswa, (3) Aspek proses adalah kinerja guru dalam kelas, dan iklim kelas.

Subjek penelitian ini adalah guru kelas IV, kepala sekolah, dan siswa. Instrumen yang digunakan dalam penelitian ini adalah peneliti sendiri karena metode yang digunakan adalah kualitatif. Penelitian ini dilakukan di sekolah SD Insan Kamil Bogor, Jl.Raya Dramaga No.13, Kecamatan Dramaga, Kota Bogor, Provisi Jawa Barat. Pada tanggal 18 Februari-20 April 2021 peneliti melewati proses penelitian ada (2) tahap, yaitu: data dikumpulkan dibulan Maret dan peneliti menganalisis data pada data temuan pada bulan April.

\section{C.Hasil Penelitian dan Pembahasan}

Hasil wawancara dengan kepala sekolah dan guru kelas IV terhadap evaluasi konteks dengan indikator tujuan pembelajaraan tematik, lingkungan sekolah, dan kebutuhan pada pembelajaraan tematik di SD Insan Kamil Bogor, Jl.Raya Dramaga No.13, Kecamatan Dramaga, Kota Bogor, Provisi Jawa Barat. bahwa hasil tujuan pembelajaraan tematik mendapat kategori "Baik". di Indonesia saat ini 
kondisi pendidikan belum secara utuh mencapai tujuan sebagaimana yang dikemukakan diatas. Berbagai hal menjadi faktor pemicu ketidak berhasilan tersebut. Lestari, dkk ( 2015:115) Kondisi nyata di sekolah yang ada di Indonesia saat ini khususnya pada pendidikan dasar adalah minimnya nilai pendidikan yang muncul dalam proses pembelajaraan.

Indikator lingkungan sekolah pada pembelajaraan tematik mendapat masuk dalam kategori "Sangat Baik". Penerapan Blended Learning tepat untuk mengatasi tantangan pendidikan tersebut. Dengan Blended Learning guru dapat memberikan inovasi pada proses pembelajaraan karena bila tidak memberikan inovasi maka guru tidak akan memperoleh hasil pembelajaraan yang tidak diharapkan dan dimasa depan pula peran guru akan dapat tergantikan oleh teknologi, seperti yang diungkapkan oleh Direktur Diktis, Prof. Dr. Dede Rosyada (Berita Diktis: 2014; dalam Sari, 2014: 134) bahwa pembelajaraan dengan sistem konvensional tatap muka (face-toface) saat ini masih kurang sesuai dengan perkembangan teknologi, ditinjau dari indikator kebutuhan pada pembelajaraan tematik masuk dalam kategori "Baik". Dalam penilaian hasil akhir proses pembelajaraan semata dikelas, guru seringkali memandang proses penilaian tersebut secara naif dan sederhana, dan secara subjektif (Suwandhono, 2016). Penilaian yang digunakan guru saat ini masih sangat kurang efisien, karena penilaian yang guru lakukan masih bersifat manual. Sedangkan penilaian merupakan salah bagian penting dari kegiatan pembelajaraan untuk melihat pencapaian taraf keberhasilan. Lestari, dkk (2020:208)

$\begin{array}{ccr}\text { Hasil } & \text { evaluasi pada } \\ \text { pembelajaraan } & \text { Blended Learning }\end{array}$
yaitu kegiatan pembelajaraan dapat dilakukan di kelas maupun di luar kelas dengan memanfaatkan teknologi untuk menambah materi pelajaran dan soal-soal yang diberikan di kelas maupun melalui online yang dikelola dan dikontrol sedemikan rupa oleh guru supaya kegiatan pembelajaraan dapat berlangsung, serta komunikasi antar siswa dan antara guru dengan siswa dapat terjalin baik ketika berada di kelas maupun di luar kelas (online) dengan membentuk sebuah grup diskusi yang memanfaatkan 
perkembangan teknologi di era ini karena pembelajaraan tanpa ada komunikasi tidak akan memberikan hasil sesuai dengan harapan baik dari guru mapun siswa.mendapat masuk dalam kategori "Sangat Baik". Gaya belajar siswa yang menggunakan visual dan audio mungkin akan berhasil akan tetapi gaya belajar siswa yang kinestetik mungkin tidak akan mencapai hasil yang diharapkan serta komunikasi dan interaksi antar siswa dan antara siswa dengan guru yang dilakukan secara berulang atau terus menerus baik di sekolah maupun di luar sekolah akan membangun jiwa sosialisai yang baik. Untuk mengatasi permasalahan tersebut perlu adanya strategi pengorganisasiaan pengajaraan, penyampaian pengajaraan, dan kualitas pengajaraan yang tidak meninggalkan pembelajaraan tatap muka di kelas (face-to-face) dan dapat memanfaatkan perkembangan teknologi yang tersedia. Dengan begitu ketertarikan dari proses pembelajaraan tersebut akan muncul dan memperoleh hasil sesuai dengan harapan untuk guru dan juga siswa. Fasilitas belajar pada pembelajaraan tematik mendapat kategori "Baik". Menurut Lestari dalam Pelaksanaan
Evaluasi Pembelajaraan Pada Masa Pandemi Covid-19 (hlm.116-117) Evaluasi pembelajaraan berfungsi untuk dua hal, yakni penilaian ketercapaian program dan tujuan pembelajaraan, dan mengukur kompetensi pencapaian siswa. Dengan adanya evaluasi guru akan lebih mudah untuk meningkatkan ataupun memperbaiki kualitas dari pembelajaraan yang telah dilaksanakan. Bahkan guru yang selalu melakukan evaluasi pembelajaraan dapat dikatakan sebagai guru yang memiliki target pencapaian pembelajaraan siswanya. Pengenalan yang dilakukan sejak dini terhadap informasi teknologi mendorong siswa lebih kreatif dan memiliki rasa ingin tahu yang tinggi. Lestari, dkk (2015:29) Berdasarkan hasil evaluasi proses masuk dalam kategori "Kurang". Indikator ikliim kelas pada pembelajaraan tematik mendapat masuk dalam kategori "Sangat Baik". Sebagian siswa merasa pembelajaraan tatap muka sudah tidak efektif lagi dan membuat mereka cepat merasa bosan. Mereka lebih tertarik memanfaatkan perkembangan teknologi yang ada untuk melakukan proses pembelajaraan yaitu dengan $E$ - 
learning. Ketertarikan E-learning di era 21 ini memang besar karena dengan semakin luasnya perkembangan teknologi dapat mempermudah siswa dalam melakukan proses pembelajaraan dimana saja dan kapan pun. Ketertarikan itu sendiri merupakan kemampuan seseorang atau suatu hal dalam memikat dan menarik seseorang untuk menyukai suatu objek. Ketertarikan dapat timbul karena terdapat suatu keunikan atau ciri khas dan kemudahan dalam menggunakan atau memahami suatu hal. Dalam proses pembelajaraan, ketertarikan perlu dimiliki supaya dapat menarik atau memikat siswa ke dalam proses pembelajaraan. Untuk dapat memunculkan ketertarikan pada proses pembelajaraan, guru perlu memiliki strategi pengorganisasian pengajaraan dan penyampaian pengajaraan yang tepat, unik, dan memberikan kemudahan pada para siswa saat proses pembelajaraan. Dengan memiliki strategi pengorganisasian pengajaraan dan penyampaian pengajaraan yang tepat mereka dapat tertarik dengan mata pelajaran atau bidang studi tersebut.

Guru merupakan fasilitator yang diperlukan siswa dan guru berperan besar membina siswa untuk memiliki sikap mental dan intelektual yang baik. Guru profesonal adalah guru yang tahu tupoksinya dan selalu mengevaluasi kinerja yang dilakukan. Evaluasi diri yang dilakukan guru adalah cara untuk mengetahui kelebihan dan kekurangan yang terjadi dalam pembelajaraan. Evaluasi diri yang dilakukan guru secara rutin, diharapkan dapat meningkatkan kualitas pembelajaraan yang muaranya akan menghasilkan lulusan yang bermutu. Lestari, dkk (2016:13)

Menurut Degeng (1989), strategi pengorganisasian pengajaraan dan penyampaian pengajaraan memiliki peran penting dalam memberikan dan mempertahankan ketertarikan bidang studi atau mata pelajaran. Tidak hanya strategi pengorganisasian dan penyampaian pengajaraan yang memiliki peran penting pada proses pembelajaraan, akan tetapi kualitas pengajaraan juga memiliki peran penting. Mengapa kualitas pengajaraan juga memiliki peran penting pada proses pembelajaraan? Karena kualitas pengajaraan dapat mempengaruhi hasil yang diperoleh pada pembelajaraan. Menurut Degeng (1989), "Kualitas pengajaraan selalu terkait pada penggunaan model 
Didaktik : Jurnal IImiah PGSD STKIP Subang, ISSN Cetak : 2477-5673 ISSN Online : 2614-722X Volume 07 Nomor 01, Juni 2021

pengajaraan yang sesuai dengan kebutuhan dalam mencapai hasil yang diharapkan dengan kondisi pengajaraan tertentu". Dengan demikian bila ingin mencapai hasil sesuai dengan harapan baik dari siswa maupun guru maka guru perlu memiliki strategi pengorganisasian pengajaraan, penyampaian pengajaraan, dan kualitas pengajaraan yang tepat apalagi di era 21 ini yang sebagian besar siswa ingin pembelajaraan tatap muka di kelas (face-to-face) ditiadakan dan melakukan proses pembelajaraan secara online dengan memanfaatkan perkembangan teknologi serta sebagian siswa mash ingin tetap menggunakan pembelajaraan tatap muka (face-to-face).

\section{a) Komponen Evaluasi Konteks}

Hasil wawancara dengan kepala sekolah dan guru kelas IV secara umum sudah baik. Secara umum hasil evaluasi konteks pembelajaraan tematik menunjukkan hasil yang baik. Artinya ditinjau dari tujuan pembelajaraan tematik, lingkungan SD Insan Kamil Bogor, Jl.Raya Dramaga No.13, Kecamatan Dramaga, Kota Bogor, Provisi Jawa Barat. maupun ditinjau dari kebutuhan yang ada pada pembelajaraan tematik kelas IV di Sekolah kesemuanya masuk dalam kategori baik. Namun, kenyataan yang ditemukan dari hasil penelitian memperlihatkan bahwa tujuan program pembelajaraan tematik yang baik tidak diaplikasikan dengan benar pada kegiatan pelaksanaan pembelajaraan sehingga tujuan tersebut belum tercapai maksimal.

b) Komponen Evaluasi Input Hasil penilaian terhadap aspek penyusunan silabus dan RPP (Rencana Pelaksanaan Pembelajaraan) pembelajaraan tematik di SD Insan Kamil Bogor, JI.Raya Dramaga No.13, Kecamatan Dramaga, Kota Bogor, Provisi Jawa Barat. Penelitian ini, masuk dalam kategori sangat baik. Namun masih ada silabus yang digunakan tidak sesuai dengan tahun berjalan dan tidak mencantumkan tahun pelajaran. Ini berarti silabus dan RPP (Rencana

Pelaksanaan Pembelajaraan) kemungkinan besar tidak direvisi oleh guru sebelum digunakan. Hal ini harus menjadi perhatian bagi guru karena silabus dan RPP (Rencana Pelaksanaan Pembelajaraan) adalah pedoman dan petunjuk bagi guru ke arah mana 
pembelajaraan akan dibawa sesuai tujuan yang akan dicapai.

Aspek fasilitas belajar masuk berkriteria baik. Namun masih ada fasilitas belajar yang harus mendapatkan perhatian yaitu, ketersediaan buku-buku paket, alat peraga, dan media pembelajaraan yang seharusnya mendukung pembelajaraan tematik belum terpenuhi. Hal penting yang juga harus diperhatikan pula oleh guru penataan kelas sesuai dengan tema yang dilaksanakan dan dapat membangkitkan motivasi belajar siswa terhadap pelajaran yang akan diterima. Aspek motivasi belajar siswa masuk dalam kategori sangat baik.

c) Komponen Evaluasi Proses

Evaluasi pada aspek kinerja guru dalam kelas secara umum untuk kinerja guru dalam kelas memiliki skor penilaian yang paling rendah dibandingkan dengan aspek evaluasi yang lain dan hanya masuk dalam kategori kurang baik, sebab pembelajaraan yang seharusnya terlaksana secara tematik tidak terjadi. Guru lebih kearah kegiatan apembelajaraan berdasarkan mata pelajaraan bukan dengan pembelajaraan tematik.

Indikator kemampuan mengelola pembelajaraan yang harus mendapatkan perhatian oleh guru adalah pada pelaksanaan pembelajaraan sesuai silabus dan RPP (Rencana Pelaksanaan Pembelajaraan). Penyusunan Silabus Dan RPP (Rencana Pelaksanaan Pembelajaraan) Sudah Sangat Baik Namun Dalam Penerapannya Guru Justru Melenceng Dari RPP (Rencana Pelaksanaan Pembelajaraan) yang telah dibuat. Selain itu penggunaan sumber belajar/media pembelajaraan serta keterlibatan siswa dalam penggunaan sumber belajar/media pembelajaraan tematik juga perlu mendapatkan perhatian karena dengan terlibat langsung siswa banyak melakukan kegiatan belajar seperti mengamati, melakukan, mendemonstrasikan, kerjasama dan sebagainya sehingga siswa dapat memperoleh pengalaman langsung dan terlatih untuk menemukan sendiri pengetahuan yang dipelajarinya. Aspek iklim kelas masuk dalam kategori sangat baik. 
Didaktik : Jurnal IImiah PGSD STKIP Subang, ISSN Cetak : 2477-5673 ISSN Online : 2614-722X Volume 07 Nomor 01, Juni 2021

\section{d) Komponen Evaluasi}

Aspek hasil belajar siswa pada pembelajaraan tematik di SD Insan Kamil Bogor, JI.Raya Dramaga No.13, Kecamatan Dramaga, Kota Bogor, Provisi Jawa Barat. Untuk kelas IV masuk dalam kategori baik. Hal tersebut seharusnya mendapat perhatian, terutama melalui pembenahaan kualitas atau komponen proses, seperti pada penelitian yang telah dilakukan. Untuk itu para guru harus senantiasa mau belajar dan melakukan evaluasi diri untuk tetap berinovasi dalam kegiatan belajar mengajar tematik siswa dapat mencapai sasaransasaran pembelajaraan tematik baik dalam aspek akademik, spritual maupun budi pekerti dan moral siswa.

\section{E. Kesimpulan}

Kesimpulan Berdasarkan hasil penelitian dan pembahasan evaluasi yang meliputi komponen konteks, input, proses, pada program pembelajaraan tematik di Sekolah SD Insan Kamil Bogor, Jl.Raya Dramaga No.13, Kecamatan Dramaga, Kota Bogor, Provisi Jawa Barat. dapat disimpulkan bahwa hasil Peranan
Blended Learning Terhadap Evaluasi Pembelajaraan Tematik Di Sekolah Dasar masuk dalam kategori baik karena guru tidak menyadari betul latar belakang dan arti penting pembelajaraan tematik bagi siswa di kelas awal. Hasil evaluasi input pembelajaraan tematik masuk dalam kategori baik. Perlu adanya ketersediaan fasilitas belajar yang lebih memadai karena program pembelajaraan tematik harus didukung oleh buku-buku paket yang baru, alat peraga yang kreatif dan menarik serta media pembelajaraan yang didukung oleh teknologi informasi dan komunikasi.

Secara umum hasil evaluasi proses pembelajaraan tematik masuk dalam kategori cukup baik karena guru tidak melakukan pembelajaraan tematik namun lebih cenderung ke pembelajaraan mata pelajaran saja. Perlu adanya pembenahan terutama melalui pembenahan kualitas atau proses sehingga siswa dapat mencapai sasaran pembelajaraan tematik baik dalam aspek akademik, spritual maupun budi pekerti dan moral siswa, serta pendukung pelaksanaan penilaian autentik meliputi fasilitas sekolah, buku guru sebagai pedoman, diskusi antar guru, 
pelatihan, dan pola kepemimpinan kepala sekolah sedangkan faktor penghambat pelaksanaan penilaian autentik meliputi kurangnya sosialisasi, alokasi waktu, dan kurangnya pengetahuan orang tua siswa.

\section{DAFTAR PUSTAKA}

Alam, M., \& Sekolah, D. I. (2015).

Pengembangan Model

Pembelajaraan Seni Lukis Berbantuan Aplikasi Tux Paint Guna Meningkatkan Kemampuan Menggambar Alam Di Sekolah Dasar. Journal of Research and Educational Research Evaluation, 4(1), 2833.

Hidayat, M. T., Junaidi, T., \& Yakob, M. (2020). Pengembangan Model Pembelajaraan Blended Learning dalam Meningkatkan Pemahaman Siswa Terhadap Tradisi Lisan Aceh. Jurnal Mimbar IImu, 25(3), 401-410.

Karli, H. (2018). Evaluasi Pelaksanaan Pembelajaraan Tematik Kurikulum 2013 Revisi 2016 di Sekolah Dasar. (29), 1529.

Moha, I., \& sudrajat, D. (2019). Resume Ragam Penelitian Kualitatif. https://doi.org/10.31227/osf.io/wt $\mathrm{ncz}$
Rachman, A., Sukrawan, Y., \& Rohendi, D. (2019). Penerapan Model Blended Learning Dalam Peningkatan Hasil Belajar Menggambar Objek 2 Dimensi. Journal of Mechanical Engineering Education, 6(2), 145-152. Retrieved from https://ejournal.upi.edu/index.php /jmee/article/view/21784

Seni, P., Aktif, T., \& Kreatif, I. D. A. N. (2015). Pembelajaraan Seni Tari: Aktif, Inovatif Dan Kreatif. Catharsis, 4(2), 115-122.

Sugiyono. 2018. Metode Penelitian Kualitatif. Bandung: ALFABETA.

Sugiyono. 2016. Metode Penelitian Pendidikan Pendekatan Kuantitatif, Kualitatif, dan $R$ \& $D$. Bandung: ALFABETA.

Wardani, D. N., Toenlioe, A. J. E., \& Wedi, A. (2018). Ketertarikan Pembelajaraan Di Era 21 Dengan Blended Learning. Jurnal Kajian Teknologi Pendidikan (JKTP), 1(1), 13-18. Retrieved from https://core.ac.uk/download/pdf/2 87323676.pdf

Yunus, G. A., Raharjo, T. J., \& Lestari, W. (2016). Pengembangan Model Supervisi Akademik Berbasis Evaluasi Diri Bagi Guru Sma. Educational Management, 5(1), 12-22.

Zainuddin, Z., \& Keumala, C. M. (2018). Blended Learning Method Within Indonesian Higher 
Didaktik : Jurnal IImiah PGSD STKIP Subang, ISSN Cetak : 2477-5673 ISSN Online : 2614-722X

Volume 07 Nomor 01, Juni 2021

Education Institutions. Jurnal

Pendidikan Humaniora, 6(2), 69-

77. Retrieved from

http://journal.um.ac.id/index.php/j

phpISSN:2338-

8110/elSSN:2442-3890 